\title{
Successional changes in the chicken cecal microbiome during 42 days of growth are independent of organic acid feed additives
}

\author{
Brian B Oakley ${ }^{1,2^{*}}$, R Jeff Buhr ${ }^{1}$, Casey W Ritz ${ }^{3}$, Brian H Kiepper $^{3}$, Mark E Berrang ${ }^{4}$, Bruce S Seal ${ }^{1}$ and Nelson A Cox ${ }^{1}$
}

\begin{abstract}
Background: Poultry remains a major source of foodborne bacterial infections. A variety of additives with presumed anti-microbial and/or growth-promoting effects are commonly added to poultry feed during commercial grow-out, yet the effects of these additives on the gastrointestinal microbial community (the Gl microbiome) as the bird matures remain largely unknown. Here we compared temporal changes in the cecal microbiome to the effects of formic acid, propionic acid, and medium-chain fatty acids (MCFA) added to feed and/or drinking water.

Results: Cecal bacterial communities at day of hatch ( $n=5$ birds), $7 d(n=32), 21 d(n=27)$, and $42 d(n=36)$ post-hatch were surveyed using direct 454 sequencing of $16 \mathrm{~S}$ rRNA gene amplicons from each bird in combination with cultivation-based recovery of a Salmonella Typhimurium marker strain and quantitative-PCR targeting Clostridium perfringens. Treatment effects on specific pathogens were generally non-significant. S. Typhimurium introduced by oral gavage at day of hatch was recovered by cultivation from nearly all birds sampled across treatments at $7 \mathrm{~d}$ and $21 \mathrm{~d}$, but by $42 \mathrm{~d}$, S. Typhimurium was only recovered from ca. $25 \%$ of birds, regardless of treatment. Sequencing data also revealed non-significant treatment effects on genera containing known pathogens and on the cecal microbiome as a whole. In contrast, temporal changes in the cecal microbiome were dramatic, highly significant, and consistent across treatments. At 7d, the cecal community was dominated by three genera (Flavonifractor, Pseudoflavonifractor, and a Lachnospiracea sequence type) that accounted for more than half of sequences. By $21 \mathrm{~d}$ post-hatch, a single genus (Faecalibacterium) accounted for $23-55 \%$ of sequences, and the number of Clostridium 16S rRNA gene copies detected by quantitative-PCR reached a maximum.

Conclusions: Over the $42 \mathrm{~d}$ experiment, the cecal bacterial community changed significantly as measured by a variety of ecological metrics and increases in the complexity of co-occurrence networks. Management of poultry to improve animal health, nutrition, or food safety may need to consider the interactive effects of any treatments with the dramatic temporal shifts in the taxonomic composition of the cecal microbiome as described here.
\end{abstract}

\section{Background}

Foodborne pathogens reportedly accounted for 47 million episodes of illness and over 100,000 hospitalizations at an estimated cost of $\$ 77$ billion in the United States in 2011 $[1,2]$. Foodborne illnesses are commonly associated with consumption of mishandled or improperly cooked poultry despite several decades of basic and applied food safety research. Interventions designed to reduce the incidence of

\footnotetext{
* Correspondence: boakley@westernu.edu

'Poultry Microbiological Safety Research Unit, USDA Agricultural Research Service, 950 College Station Road, Athens, GA 30605, USA

${ }^{2}$ Western University of Health Sciences, College of Veterinary Medicine, 309 E. 2nd St, Pomona, CA 91766, USA

Full list of author information is available at the end of the article
}

poultry-associated foodborne illness are generally targeted either to the later stages of poultry processing such as chlorinated chill tanks commonly used in the U.S $[3,4]$, or onfarm interventions which seek to reduce pathogen loads at various stages of the production process prior to processing [5]. Feed additives that can modulate the gastrointestinal microbial community (the GI microbiome) have been the subject of intense and increasing interest following the 2006 European Union ban on prophylactic antibiotics added to feed as growth promoters [6] and calls for similar regulation in the U.S. [7-9].

To evaluate the efficacy and utility of alternative antimicrobial feed additives, two main parameters need to 
be evaluated: 1) the effect of the additive on the pathogen(s) of interest, and 2) the effects of the additive on the GI microbiome of the host. The importance of GI microbial communities for the health and nutrition of the host organism is now well established [10-14], and removing antibiotics from feed (as proposed by recent FDA guidance for industry) has previously been shown to induce various changes within the chicken GI microbiome [15-18]. Developing acceptable alternatives to antibiotics will thus require assessing their effect on specific pathogens and the GI microbiome.

To date, a number of studies have examined the effects of various alternative antimicrobial feed additives on GI microbial communities of poultry [15,19-25], but only recently have a few studies [26-29] utilized the power of modern high-throughput sequencing (HTS) to provide a comprehensive taxonomic census and fully assess the effects of treatments on the GI microbiome. Methods commonly used in the past have some important shortcomings, including extreme taxonomic bias (cultivation-based approaches), low taxonomic resolution (DGGE, T-RFLP), or inadequate depth of sampling (Sanger-sequenced clone libraries). Another important aspect of any evaluation of a feed additive is determining how any treatment effects interact with natural successional changes in the GI microbiome. Dramatic changes in community composition and function have been shown to occur naturally as birds mature [18,30-33], although most of these previous studies share the same methodological limitations discussed above and thus are in need of revisiting with modern methods.

In this work we combine 454 pyrosequencing of broadrange 16S rRNA gene amplicons, quantitative-PCR, and cultivation-based recovery of a pathogenic marker strain to document the successional development and effects of feed additives on the cecal microbiome and specific pathogens. By sequencing a population of amplicons to exhaustion, HTS performs a comprehensive census free of cultivation bias; these taxonomic data are necessary to improve understanding of the community structure of the poultry cecal microbiome and how it changes as birds mature to market age. The work presented here had two main objectives: 1) determine the relative effects of organic acid feed additives and successional changes in the poultry cecal microbiome at the community level using HTS and on the pathogens Salmonella and Clostridium using cultivation and GPCR respectively, and 2) provide a comprehensive data set of the taxonomic composition of the cecal microbiome in broilers as they grow to market age.

\section{Results and discussion}

Effects of treatments versus time on cecal microbiome

Temporal changes in the cecal microbiome were dramatic, highly significant, and consistent across treatments.
Clustering of the cecal microbiome from each bird at the OTU level using CCA as described in the methods showed clear groupings by time that were much stronger than any treatment effect (Figure 1). To explicitly test the relative effects of time versus experimental treatments on the cecal microbiome, permutational MANOVA was used as described in the methods. The effect of time was highly significant $(\mathrm{p}<0.0001)$ whereas experimental treatment effects were non-significant (Table 1). Clustering and hypothesis testing using taxonomic classifications of sequences to the genus level gave with the RDP classifier or Silva database equivalent results.

To document the composition of the cecal microbiota and examine specific changes through time and by treatment, sequences were classified taxonomically. At $7 \mathrm{~d}$, the cecal community was dominated by three genera (Flavonifractor, Pseudoflavonifractor, and Lachnospiracea incertae sedis; the latter sequences mostly classified as Blautia or Ruminococcus by usearch against the Silva database) that accounted for more than half of sequences (Figure 2). These three groups all belong to the Clostridiales with Flavonifractor and Pseudoflavonifractor quite closely related phylogenetically. Blautia has recently been identifed as a ubiquitious (though low abundance) taxon present in humans and various animals [34], and members of the Clostridiales are well known for their conversions of complex polysaccharides to short chain fatty acids such as butyrate that have significant positive growth effects [35,36].

By $21 \mathrm{~d}$ post-hatch, a single genus (Faecalibacterium) accounted for $23-55 \%$ of sequences (Figure 2). Faecalibacterium prausnitzii has been shown to have antiinflammatory properties and an inverse correlation with severity and recurrence of colitis in humans and murine models [37]. Whether or not members of the genus Faecalibacterium have similar roles in chickens remains an interesting question. By 42d, Faecalibacterium sequences were recovered at approximately equal proportions to Roseburia, a saccharolytic, butyrate-producing bacterium [38]. Also relatively abundant at $42 \mathrm{~d}$ were sequences classified as Lachnospiracea incertae sedis, and Oscillibacter, previously encountered in chickens [39] and with some members known to produce short chain fatty acids [40,41]. These data are consistent with previous results identifying various members of the poultry GI microbiome $[15,19-25,42]$, but by exhaustive sequencing with modern methods from a fairly large number of birds, also provide important new information regarding the generic composition of the chicken cecal microbial community and how it changes through time. Proper understanding and management of temporal changes in the GI microbiome will be important for maintaining bird health and improving productivity. 


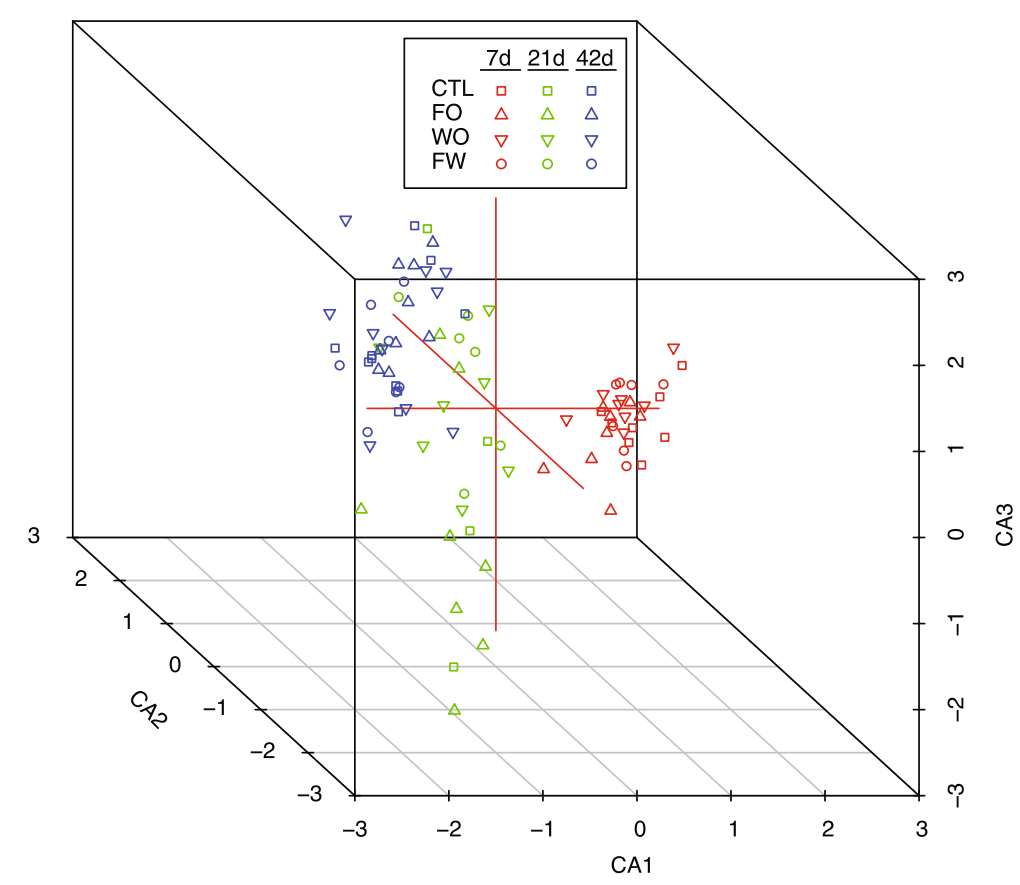

Figure 1 Clustering of the cecal microbiome by treatment and time. Clustering was performed by canonical correspondence analysis as described in the text. Each point represents a single bird with sequences clustered independent of taxonomic assignments according to operational taxonomic units (OTUs) defined at a $97 \%$ similarity cutoff as described in the text. Data from day-of-hatch birds group off of the axes and are excluded for clarity. Clustering based on classification of sequences to the genus or species level gave equivalent results. Treatment designations are $\mathrm{Ctl}$, control; FO, feed-only; WO, water-only; and FW, feed and water as described in the text.

Effects of treatments versus time on specific pathogens Treatment effects on specific pathogens were generally non-significant. The marker strain of S. typhimurium was recovered from nearly all birds sampled at $7 \mathrm{~d}$ and $21 \mathrm{~d}$, regardless of treatment, and by $42 \mathrm{~d}$, few differences were observed across the treatments with the marker strain recovered from ca. $1 / 4$ of treated and untreated birds (Table 2). Importantly, from $21 \mathrm{~d}$ to $42 \mathrm{~d}$ the proportion of birds from which Salmonella was recovered across all treatments decreased from a mean of $94 \%$ to 26\% (Table 2).

Sequencing data also demonstrated small treatment effects on taxonomic groups containing known pathogens (Figure 3). Consistent with the cultivation data, Salmonella sequences decreased in relative abundance with time and were almost entirely absent by $21 \mathrm{~d}$ (Figure 3A). Sequences classified as Clostridium increased to a maximum of $0.5 \%$ at $21 \mathrm{~d}$, subsequently decreasing in relative abundance at $42 \mathrm{~d}$. (Figure $3 \mathrm{~A}$ ). In general, taxa considered as putative pathogens (Campylobacter, Clostridium, Escherichial Shigella, Klebsiella, and Salmonella) were a minor component of the community $(<1.5 \%$ total relative abundance). Quantitative-PCR for the Clostridium clade containing the C. perfringens subgroup was qualitatively consistent with the sequencing data and showed a significant increase in the abundance of this group from day of hatch to $21 \mathrm{~d}$ posthatch, followed by a significant decline by $42 \mathrm{~d}$ to the same levels at $7 \mathrm{~d}$ (Figure 3B).

Although the main purpose of the work presented here was to monitor the cecal microbial community as a

Table 1 Results of permutational MANOVA conducted with the adonis function in $\mathbf{R}$

\begin{tabular}{|c|c|c|c|c|c|c|}
\hline & Degrees of freedom & Sum of squares & Mean squares & F. model & $\mathrm{R}^{2}$ & $\operatorname{Pr}(>\mathrm{F})$ \\
\hline Time & 1 & 3.457 & 3.457 & 8.986 & 0.0912 & 0.0001 \\
\hline Treatment & 3 & 1.137 & 0.379 & 0.985 & 0.0300 & 0.4935 \\
\hline Time:Treatment & 3 & 1.019 & 0.340 & 0.883 & 0.0269 & 0.8455 \\
\hline Residuals & 84 & 32.310 & 0.385 & & 0.8520 & \\
\hline Total & 91 & 37.922 & & & 1.0000 & \\
\hline
\end{tabular}

Comparisons were made using OTU-level classification of the sequencing reads for each bird and 10,000 permutations. Only the effect of time on community composition was significant $(\mathrm{p}<0.0001)$. Taxonomic classifications of sequences against the RDP or Silva databases gave equivalent results. 


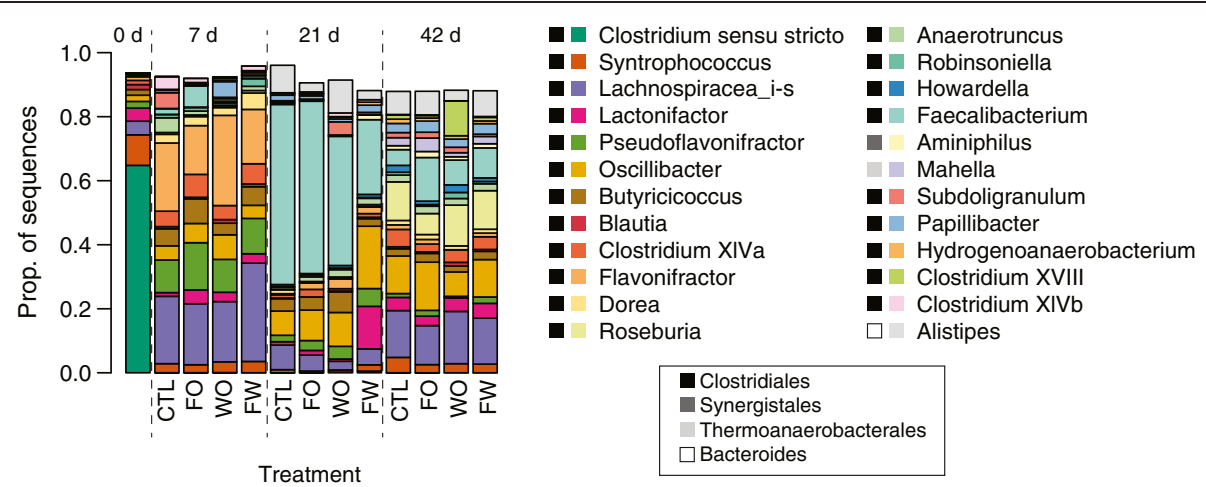

Figure 2 Relative abundance at the genus level for sequences by treatment and time with taxonomic classifications performed with the RDP classifier as described in the text. Only sequences with a total relative abundance greater than $5 \%$ are shown. For day-of-hatch birds and each subsequent time point ( $7 \mathrm{~d}, 21 \mathrm{~d}$, and $42 \mathrm{~d}$ post-hatch), the relative proportions are shown for each treatment. Day-of-hatch birds were proportionally high in Clostridium but low quantitatively as shown in Figure 3. Treatment designations are Ctl, control; FO, feed-only; WO, water-only; and FW, feed and water as described in the text.

whole, comparing the sequencing and qPCR data for Clostridium helps to validate the use of sequencing, even for relatively low abundance taxa. Assumptions of a mean genome size of $3.6 \mathrm{Mbp}$ [43] and bacterial cell densities in the chicken cecum of $10^{10}-10^{11}$ cells $\mathrm{g}^{-1}$ [44], gives approximately $4 \times 10^{4} \mathrm{ng}$ bacterial DNA $\mathrm{g}^{-1}$ of cecal contents. Further, applying an extraction efficiency assumption of $14 \%$ [45] to the qPCR data at $21 \mathrm{~d}$ post-hatch where ca. $100 \mathrm{C}$. perfringens group rRNA gene copies were observed $\mathrm{ng}^{-1}$ of DNA, gives $2.8 \times 10^{6}$ cells $\mathrm{g}^{-1}$ of cecal contents, or $0.028 \%$ of a total bacterial community of $10^{10}$ cells. From the sequencing data, the proportion of Clostridium sequences at 21d post-hatch was approximately an order of magnitude greater $(0.216 \%)$, which is roughly in line particularly as the sequence data were classified at the genus level.

Clostridia are abundant numerically and proportionally in the chicken GI microbiome, particularly in the ceca $[16,46]$. Clostridium islandicum and other members of the Clostridium cluster XIV are associated with cellulytic activity [47] and feed conversion [48], while other Clostridia such as C. perfringens are veterinary pathogens causing enteric diseases in both domestic and wild

Table 2 Proportion of birds with positive culture tests for marker strain of Salmonella Typhimurium recovered from cecal samples

\begin{tabular}{llll}
\hline Treatment & 7d & $\mathbf{2 1 d}$ & $\mathbf{4 2 d}$ \\
\hline Ctl & $8 / 8$ & $3 / 4$ & $7 / 20$ \\
WO & $8 / 8$ & $4 / 4$ & $5 / 20$ \\
FO & $8 / 8$ & $4 / 4$ & $4 / 20$ \\
FW & $8 / 8$ & $4 / 4$ & $5 / 20$ \\
Total & $100 \%$ & $94 \%$ & $26 \%$ \\
\hline
\end{tabular}

Treatment designations are Ctl, control; FO, feed-only; WO, water-only; and FW, feed and water. Cultivation media and methods are described in detail in the text. animals, gas gangrene (clostridial myonecrosis), necrotic enteritis, and gastrointestinal infections in humans [49-51]. As the mechanisms for colonization of the avian intestinal tract and the factors involved in toxin production remain largely unknown, few tools and strategies are currently available for prevention and control of $C$. perfringens in poultry. Vaccination against this pathogen and the use of probiotic or prebiotic products has been suggested, but are not available for practical use in the field [51]. Although no disease was overtly observed during our experiment, low levels of $C$. perfringens were detected in the ceca of treated and untreated chickens.

Through the course of the experiment, the cecal community became more taxonomically rich and diverse. The number of genera more than doubled to $>200$ at $42 \mathrm{~d}$ and diversity increased similarly (Figure 4). Network analysis performed on the cecal microbiome at each time point also showed an increase in complexity with the number of nodes (taxa with significant co-occurrence patterns with other taxa), increasing through time (92, 122, and 147 nodes at $7 \mathrm{~d}, 21 \mathrm{~d}$ and $42 \mathrm{~d}$ respectively; Figure 4 ). Previously, increases in taxonomic richness as birds mature has been inferred from the number of bands on DGGE gels [30,32], TRFLP fingerprints, and sequencing [33]. Metagenomic approaches have provided important insights into the poultry cecal microbiome [52] and the effects of antimicrobials [18], but 16S rRNA-based taxonomic profiling provides the most relevant information for food-safety regulations and the development of probiotic or other alternatives to antibiotics, such as phage-lytic enzymes.

\section{Conclusions}

Although organic acids as feed additives have been proposed as a management strategy in various formulations to combat pathogens in poultry [53-58], we found little effect of the treatments tested here on specific pathogens or 


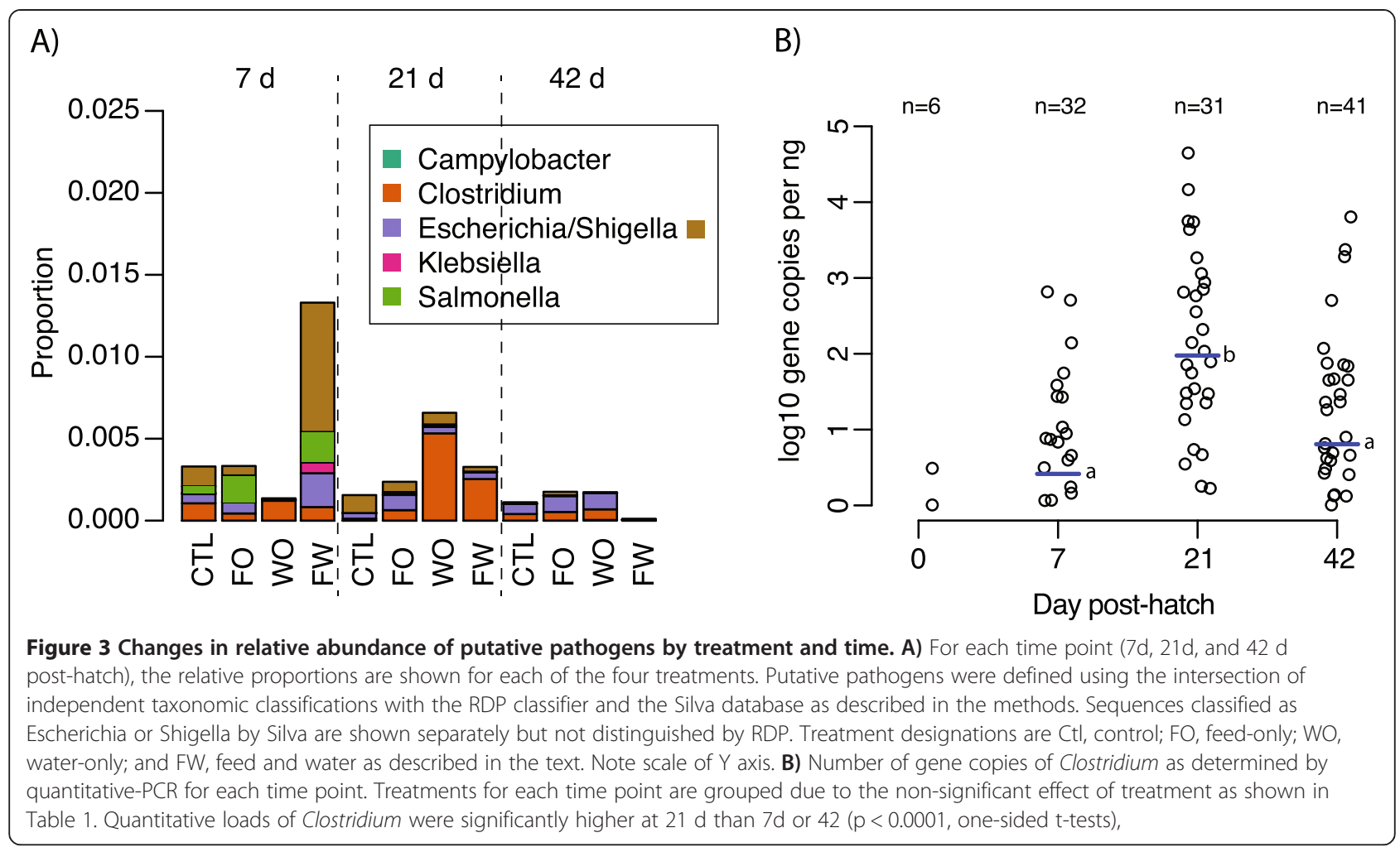

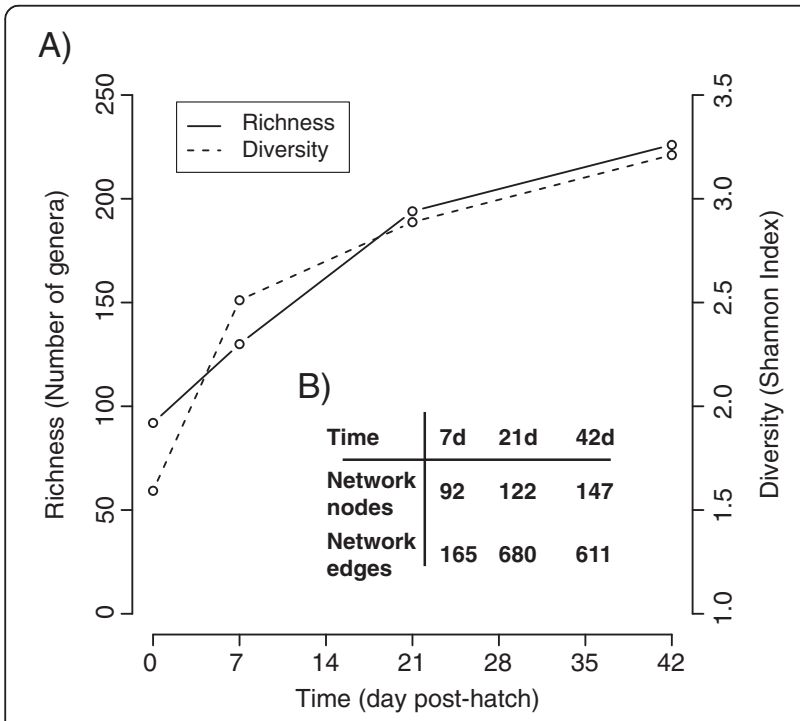

Figure 4 Taxonomic richness and diversity of the cecal microbiome at the genus level through time. A) Richness and diversity statistics calculated at the species and OTU-level showed essentially similar patterns through time. B) Network complexity of the cecal microbiome through time as measured by the numbers of nodes and edges in network. Nodes represent genera with significant network connections to other genera and edges represent the total number of significant networks connections calculated as described in the text. the cecal microbiome in general. We did observe dramatic changes in the cecal microbiome through time, consistent with earlier work [33], and for the first time, detail these changes taxonomically using high-throughput sequencing. During the $42 \mathrm{~d}$ of the experiment, the cecal microbiome became significantly more taxon-rich and diverse according to a variety of ecological metrics and increases in network complexity. The temporal dynamics of the poultry GI microbiome need to be considered in the proper management of poultry for productivity, animal health, and food safety.

\section{Methods \\ Experimental procedures}

A total of 480 male chicks (Ross $\times$ Cobb broilers) in a feeding trial were given one of four experimental feeding treatments beginning at day of hatch: 1) a solution of formic acid $\left(\mathrm{CH}_{2} \mathrm{O}_{2} ; 340 \mathrm{ppm}\right.$ final concentration), propionic acid $\left(\mathrm{C}_{3} \mathrm{H}_{6} \mathrm{O}_{2} ; 250 \mathrm{ppm}\right)$, ammonium formate $\left(\mathrm{NH}_{4} \mathrm{HCO}_{2} ; 200 \mathrm{ppm}\right.$ medium-chain fatty acids (MCFA; $100 \mathrm{ppm})$, an emulsifier (50 ppm), and propylene glycol $(1 \mathrm{ppm})$ added to the drinking water $(\mathrm{n}=120), 2)$ propionic acid (480 ppm) and MCFA (1520 ppm) added to the feed $(n=120), 3)$ a combination of treated feed and water at the same concentrations $(n=120)$, or 4$)$ control birds receiving a standard nonmedicated corn-soybean $\operatorname{diet}(\mathrm{n}=120)$. These treatments are hereafter referred to 
according to the treated component as water-only (WO), feed-only (FO), feed and water (FW), or control (CTL). Day of hatch chicks were placed on clean pine shavings in ca. $1 \mathrm{~m} \mathrm{x} 3 \mathrm{~m}$ floor pens with feed and water (via nipple drinker lines) provided ad libitum. Each of the four treatments included four replicate pens for a total of 16 pens, each containing 30 birds. Within each pen, two birds were orally inoculated as 'seeder birds' with $0.1 \mathrm{~mL}$ of a $10^{7}$ cells $\mathrm{ml}^{-1}$ suspension of a nalidixic acid resistant strain of Salmonella Typhimurium. At each of four time points $(0,7,21$, and $42 \mathrm{~d}$ post-hatch), ceca were collected for cultivation and DNA extractions as previously described [59]. Sample sizes and details are shown in Table 3. Ethical approval of animal work was granted under University of Georgia animal use permit A2012 02-002-Y2-A0.

\section{Quantitative-PCR, 454 sequencing and data analysis}

Quantitative-PCR assays for the $C$. perfringens group were performed as previously described [46] with forward (5'-ATGCAAGTCGAGCGAKG-3') and reverse (5'-TATGCGGTATTAATCTYCCTTT-3') primers from [60] and SYBR Green chemistry (ABI, Carslbad, CA).

PCR and 454 pyrosequencing of the V1-V3 regions of 16S rRNA genes were performed using tagged amplicon methods as previously described $[46,61]$. Briefly, sequences were de-multiplexed and preprocessed with the Galaxy toolkit [62] and our own custom tools [63]; additional quality controls per recent recommendations and standard protocols [64] were completed using Perl and Bioperl scripts to trim pyrosequencing tag sequences, screen for presence of the forward PCR primer sequence, and remove sequences with any ambiguous base calls. Based on expected amplicon sizes and frequency distributions of sequence lengths in v108 of the Silva reference database, sequences were further limited to a range of 325-425 bp. Putative chimeric sequences were identified with usearch [65] and ChimeraSlayer in mothur [66]. After these screening steps, the following number of sequences per treatment group were used for analysis: CTL 7d 31280; FO 7d 31174, FW 7d 33990, WO 7d 33844, CTL 21d 18902, FO 21d 25491, FW 21d 23114, WO 21d 32309, CTL 42d 38770, FO 42d
32167, FW 42d 25578, WO 42d 34168. Rarefaction curves are shown in Additional file 1: Figure S1.

Taxonomic classification of sequences was performed with the RDP naïve Bayesian classifier [67] v2.6 and the EMBL taxonomy from v115 of the Silva project curated seed database using usearch with the global alignment option [65]. To assess phylotype richness and diversity independent of taxonomic classifications, sequences which passed all the screens described above were grouped into similarity clusters (operational taxonomic units; OTUs), using similarity cutoffs of 90\%, 95\%, and 97\% with uclust [65]. The output from usearch provided the inputs for our own customized analysis pipeline to parse the clustering results and produce graphical and statistical summaries of the data for the desired sampling units using perl and $\mathrm{R}$ [68] as previously described $[61,63]$. Clustering of communities was performed using the CCA function of the vegan package [69] in R based on OTU and taxonomic classifications. The relative effects of time (number of days post-hatch) versus experimental treatment (and their interactive effects) on cecal microbial communities was determined by a permutational multivariate analysis of variance (MANOVA) using the adonis function of the vegan package in $R$. Briefly, OTU or taxonomic classifications of sequences from each bird are used to partition sums of squared deviations from centroids in a distance matrix to determine how variation is explained by experimental treatments (feed additives and/or sampling time in our case), or uncontrolled covariates [70].

Network analysis was conducted as previously described [46] using normalized OTU tables at various levels of clustering and removing OTUs or taxa represented by fewer than five sequences or $<0.5 \%$ total relative abundance across all samples. Spearman correlation coefficients of 0.7 and p-values of 0.001 were required to establish valid co-occurrence among OTUs. Network analysis was performed in $\mathrm{R}$ with the igraph package and visualized with the program Gephi.

Sequence data have been deposited in GenBank with accession numbers SAMN03161778-SAMN03161871 associated with BioProject ID 263495.

Table 3 Number of birds sampled for quantitative-PCR and 454 pyrosequencing by treatment and time

\begin{tabular}{|c|c|c|c|c|c|c|c|c|c|c|}
\hline \multirow[t]{2}{*}{ Treatment } & \multicolumn{2}{|l|}{ Od } & \multicolumn{2}{|l|}{$7 d$} & \multicolumn{2}{|l|}{$21 d$} & \multicolumn{2}{|l|}{$42 d$} & \multicolumn{2}{|c|}{ Subtotal } \\
\hline & qPCR & 454 & qPCR & 454 & qPCR & 454 & qPCR & 454 & qPCR & 454 \\
\hline $\mathrm{Ctl}$ & 6 & 6 & 8 & 8 & 7 & 4 & 10 & 10 & 31 & 22 \\
\hline Wo & $\mathrm{n} / \mathrm{a}$ & n/a & 8 & 8 & 8 & 8 & 11 & 10 & 27 & 26 \\
\hline $\mathrm{FO}$ & $\mathrm{n} / \mathrm{a}$ & n/a & 8 & 8 & 8 & 8 & 11 & 9 & 27 & 25 \\
\hline FW & $\mathrm{n} / \mathrm{a}$ & $\mathrm{n} / \mathrm{a}$ & 8 & 8 & 8 & 7 & 9 & 7 & 25 & 22 \\
\hline Subtotal & 6 & 6 & 32 & 32 & 31 & 27 & 41 & 36 & 110 & 95 \\
\hline
\end{tabular}

Treatment designations are Ctl, control; FO, feed-only; WO, water-only; and FW, feed and water. 


\section{Additional file}

Additional file 1: Figure S1. Rarefaction curves for genus (A), species (B) and 3 percent OTU (operational taxonomic unit) classifications (C). Note differences in $Y$ axis scaling.

\section{Competing interests}

The authors declare that they have no competing interests.

\section{Authors' contributions}

$\mathrm{BO}$ wrote the manuscript, analysed data, and collected samples, JB designed the study and contributed to the manuscript, $C R$ and BK helped design the study and organized the feeding trial, MB contributed to the manuscript and feeding trial, BS performed quantitative-PCR and contributed to the manuscript, NC helped design the study, organized the feeding trial, and contributed to the manuscript. All authors read and approved the final manuscript.

\section{Acknowledgements}

Funding was provided by the USDA Agricultural Research Service CRIS project 6612-32000-068 and Project \#F053 funded by the U.S. Poultry \& Egg Association. We thank Manju Amin, Dianna Bourassa, Johnna Garrish, and Jeromy Jackson, and Luanne Rigsby for excellent technical assistance. Mention of trade names or commercial products in this publication is solely for the purpose of providing specific information and does not imply recommendation or endorsement by the U.S. Department of Agriculture (USDA). USDA is an equal opportunity provider and employer. The views expressed in this chapter are those of the authors and do not necessarily represent the views or policies of the USDA.

\section{Author details}

${ }^{1}$ Poultry Microbiological Safety Research Unit, USDA Agricultural Research Service, 950 College Station Road, Athens, GA 30605, USA. ${ }^{2}$ Western University of Health Sciences, College of Veterinary Medicine, 309 E. 2nd St, Pomona, CA 91766, USA. ${ }^{3}$ Poultry Science Department, University of Georgia, Athens, GA 30602, USA. ${ }^{4}$ Bacterial Epidemiology and Antibiotic Resistance Research Unit, USDA Agricultural Research Service, Richard B. Russell Agricultural Research Center, 950 College Station Road, Athens, GA 30605, USA.

\section{Received: 22 April 2014 Accepted: 17 November 2014}

\section{W.}

\section{References}

1. Scallan E, Griffin PM, Angulo FJ, Tauxe RV, Hoekstra RM: Foodborne illness acquired in the united states-unspecified agents. Emerg Infect Dis 2011, 17:16-22.

2. Scharff RL: Economic burden from health losses due to foodborne illness in the United States. J Food Prot 2012, 75:123-131.

3. James WO, Brewer RL, Prucha JC, Williams WO Jr, Parham DR: Effects of chlorination of chill water on the bacteriologic profile of raw chicken carcasses and giblets. J Am Vet Med Assoc 1992, 200:60-63.

4. James C, Vincent C, De Andrade Lima TI, James SJ: The primary chilling of poultry carcasses-a review. Int J Refrigeration 2006, 29:847-862.

5. Doyle MP, Erickson MC: Opportunities for mitigating pathogen contamination during on-farm food production. Int J Food Microbio/ 2012, 152:54-74.

6. European-Commission: Regulation (EC) No. 1831/2003 of the European Parliament and of the Council on additives for use in animal nutrition. Official Journal of European Union 2003, L 268:29-43.

7. Weber JT, Courvalin P: An emptying quiver: antimicrobial drugs and resistance. Emerg Infect Dis 2005, 11:791-793.

8. Love DC, Davis MF, Bassett A, Gunther A, Nachman KE: Dose imprecision and resistance: Free-choice medicated feeds in industrial food animal production in the United States. Environ Health Perspect 2011, 119:279-283.

9. Seal BS, Lillehoj HS, Donovan DM, Gay CG: Alternatives to antibiotics: a symposium on the challenges and solutions for animal production. Anim Health Res Rev 2013, 14:78-87.

10. Turnbaugh PJ, Ley RE, Mahowald MA, Magrini V, Mardis ER, Gordon الـ: An obesity-associated gut microbiome with increased capacity for energy harvest. Nature 2006, 444:1027-1031.
11. McKenna P, Hoffmann C, Minkah N, Aye PP, Lackner A, Liu ZZ, Lozupone CA, Hamady M, Knight R, Bushman FD: The macaque gut microbiome in health, lentiviral infection, and chronic enterocolitis. PLOS Pathog 2008, 4:E20

12. Bakken JS, Borody T, Brandt LJ, Brill JV, Demarco DC, Franzos MA, Kelly C, Khoruts A, Louie T, Martinelli LP, Moore TA, Russell G, Surawicz C, Fecal Microbiota T: Treating clostridium difficile infection with fecal microbiota transplantation. Clin Gastroenterol Hepatol 2011, 9:1044-1049.

13. Greenblum S, Turnbaugh PJ, Borenstein E: Metagenomic systems biology of the human gut microbiome reveals topological shifts associated with obesity and inflammatory bowel disease. Proc Natl Acad Sci U S A 2012, 109:594-599.

14. Lawley TD, Clare S, Walker AW, Stares MD, Connor TR, Raisen C, Goulding D, Rad R, Schreiber F, Brandt C, Deakin LJ, Pickard DJ, Duncan SH, Flint HJ, Clark TG, Parkhill J, Dougan G: Targeted restoration of the intestinal microbiota with a simple, defined bacteriotherapy resolves relapsing clostridium difficile disease in mice. PLoS Pathog 2012, 8:e1002995.

15. Knarreborg A, Simon MA, Engberg RM, Jensen BB, Tannock GW: Effects of dietary fat source and subtherapeutic levels of antibiotic on the bacterial community in the ileum of broiler chickens at various ages. Appl Environ Microbiol 2002, 68:5918-5924.

16. Wise $M G$, Siragusa GR: Quantitative analysis of the intestinal bacterial community in one- to three-week-old commercially reared broiler chickens fed conventional or antibiotic-free vegetable-based diets. J Appl Microbiol 2007, 102:1138-1149.

17. Fairchild AS, Smith JL, Idris U, Lu J, Sanchez S, Purvis LB, Hofacre C, Lee MD: Effects of orally administered tetracycline on the intestinal community structure of chickens and on tet determinant carriage by commensal bacteria and Campylobacter jejuni. Appl Environ Microbiol 2005, 71:5865-5872.

18. Danzeisen JL, Kim HB, Isaacson RE, Tu ZJ, Johnson TJ: Modulations of the chicken cecal microbiome and metagenome in response to anticoccidial and growth promoter treatment. PLoS One 2011, 6:e27949.

19. Gong J, Yu H, Liu T, Gill JJ, Chambers JR, Wheatcroft R, Sabour PM: Effects of zinc bacitracin, bird age and access to range on bacterial microbiota in the ileum and caeca of broiler chickens. J App/ Microbio/ 2008, 104:1372-1382.

20. Torok VA, Allison GE, Percy NJ, Ophel-Keller K, Hughes RJ: Influence of antimicrobial feed additives on broiler commensal posthatch gut microbiota development and performance. Appl Environ Microbiol 2011, 77:3380-3390.

21. Tillman GE, Haas GJ, Wise MG, Oakley B, Smith MA, Siragusa GR: Chicken intestine microbiota following the administration of lupulone, a hop-based antimicrobial. FEMS Microbiol Ecol 2011, 77:395-403.

22. Sun $\mathrm{H}$, Tang JW, Fang CL, Yao XH, Wu YF, Wang X, Feng J: Molecular analysis of intestinal bacterial microbiota of broiler chickens fed diets containing fermented cottonseed meal. Poult Sci 2013, 92:392-401.

23. Oviedo-Rondon EO, Hume ME, Barbosaa NA, Sakomura NK, Weber G, Wilsone $J W$ : lleal and caecal microbial populations in broilers given specific essential oil blends and probiotics in two consecutive grow-outs. Avian Biology Research 2010, 3:157-169.

24. Geier MS, Torok VA, Allison GE, Ophel-Keller K, Gibson RA, Munday C, Hughes RJ: Dietary omega-3 polyunsaturated fatty acid does not influence the intestinal microbial communities of broiler chickens. Poult Sci 2009, 88:2399-2405

25. Bjerrum L, Pedersen K, Engberg RM: The influence of whole wheat feeding on Salmonella infection and gut flora composition in broilers. Avian Dis 2005, 49:9-15

26. Stanley D, Hughes RJ, Moore RJ: Microbiota of the chicken gastrointestinal tract: influence on health, productivity and disease. Appl Microbiol Biotechnol 2014, 98:4301-4310.

27. Videnska P, Sisak F, Havlickova H, Faldynova M, Rychlik I: Influence of Salmonella enterica serovar Enteritidis infection on the composition of chicken cecal microbiota. BMC Vet Res 2013, 9:Article number 140.

28. Singh KM, Shah TM, Reddy B, Deshpande S, Rank DN, Joshi CG: Taxonomic and gene-centric metagenomics of the fecal microbiome of low and high feed conversion ratio (FCR) broilers. J Appl Genet 2014, 55:145-154.

29. Sergeant MJ, Constantinidou C, Cogan TA, Bedford MR, Penn CW, Pallen MJ: Extensive microbial and functional diversity within the chicken cecal microbiome. PLoS One 2014, 9:e91941.

30. van der Wielen PW, Keuzenkamp DA, Lipman L, Van Knapen F, Biesterveld S: Spatial and temporal variation of the intestinal bacterial community in 
commercially raised broiler chickens during growth. Microb Ecol 2002, 44:286-293.

31. Sekelja M, Rud I, Knutsen SH, Denstadli V, Westereng B, Naes T, Rudi K: Abrupt temporal fluctuations in the chicken fecal microbiota are explained by its gastrointestinal origin. Appl Environ Microbiol 2012, 78:2941-2948.

32. Hume ME, Kubena LF, Edrington TS, Donskey CJ, Moore RW, Ricke SC, Nisbet DJ: Poultry digestive microflora biodiversity as indicated by denaturing gradient gel electrophoresis. Poult Sci 2003, 82:1 100-1107.

33. Lu J, Idris U, Harmon B, Hofacre C, Maurer JJ, Lee MD: Diversity and succession of the intestinal bacterial community of the maturing broiler chicken. Appl Environ Microbiol 2003, 69:6816-6824.

34. Eren AM, Sogin ML, Morrison HG, Vineis JH, Fisher JC, Newton RJ, McLellan SL: A single genus in the gut microbiome reflects host preference and specificity. ISME J 2014. doi:10.1038/ismej.2014.97.

35. Biddle A, Stewart L, Blanchard J, Leschine S: Untangling the genetic basis of fibrolytic specialization by lachnospiraceae and ruminococcaceae in diverse gut communities. Diversity 2013, 5:627-640.

36. Donohoe DR, Garge N, Zhang X, Sun W, O'Connell TM, Bunger MK, Bultman $\mathrm{SJ}$ : The microbiome and butyrate regulate energy metabolism and autophagy in the mammalian colon. Cell Metab 2011, 13:517-526.

37. Sokol H, Pigneur B, Watterlot L, Lakhdari O, Bermudez-Humaran LG, Gratadoux $\mathrm{JJ}$, Blugeon S, Bridonneau C, Furet JP, Corthier G, Grangette C, Vasquez N, Pochart P, Trugnan G, Thomas G, Blottiere HM, Dore J, Marteau P, Seksik P, Langella P: Faecalibacterium prausnitzii is an anti-inflammatory commensal bacterium identified by gut microbiota analysis of Crohn disease patients. Proc Natl Acad Sci U S A 2008, 105:16731-16736.

38. Duncan SH, Hold GL, Barcenilla A, Stewart CS, Flint HJ: Roseburia intestinalis sp. nov., a novel saccharolytic, butyrate-producing bacterium from human faeces. Int I Syst Evol Microbiol 2002, 52:1615-1620.

39. Luo YH, Peng HW, Wright ADG, Bai SP, Ding XM, Zeng QF, Li H, Zheng P, Su ZW, Cui RY, Zhang KY: Broilers fed dietary vitamins harbor higher diversity of cecal bacteria and higher ratio of Clostridium Faecalibacterium, and Lactobacillus than broilers with no dietary vitamins revealed by 16 S rRNA gene clone libraries. Poult Sci 2013, 92:2358-2366.

40. Lee GH, Kumar S, Lee JH, Chang DH, Kim DS, Choi SH, Rhee MS, Lee DW, Yoon MH, Kim BC: Genome sequence of Oscillibacter ruminantium strain GH1, isolated from rumen of Korean native cattle. J Bacteriol 2012, 194:6362.

41. Katano Y, Fujinami S, Kawakoshi A, Nakazawa H, Oji S, lino T, Oguchi A, Ankai A, Fukui S, Terui Y, Kamata S, Harada T, Tanikawa S, Suzuki K, Fujita N: Complete genome sequence of Oscillibacter valericigenes Sjm18-20 T (=NBRC 101213 T). Stand Genomic Sci 2012, 6:406-414.

42. Rehman HU, Vahjen W, Awad WA, Zentek J: Indigenous bacteria and bacterial metabolic products in the gastrointestinal tract of broiler chickens. Arch Anim Nutr 2007, 61:319-335.

43. Fogel GB, Collins CR, Li J, Brunk CF: Prokaryotic genome size and SSU rDNA copy number: estimation of microbial relative abundance from a mixed population. Microb Ecol 1999, 38:93-113.

44. Apajalahti JHA, Särkilahti LK, Mäki BRE, Pekka Heikkinen J, Nurminen PH, Holben WE: Effective recovery of bacterial DNA and percent-guanine-plus-cytosinebased analysis of community structure in the gastrointestinal tract of broiler chickens. Appl Environ Microbiol 1998, 64:4084-4088.

45. Claassen S, Du Toit E, Kaba M, Moodley C, Zar HJ, Nicol MP: A comparison of the efficiency of five different commercial DNA extraction kits for extraction of DNA from faecal samples. J Microbiol Methods 2013, 94:103-110.

46. Oakley BB, Morales CA, Line J, Berrang ME, Meinersmann RJ, Tillman GE, Wise MG, Siragusa GR, Hiett KL, Seal BS: The poultry-associated microbiome: network analysis and farm-to-fork characterizations. PLoS One 2013, 8:e57190.

47. Izquierdo JA, Sizova MV, Lynd LR: Diversity of bacteria and glycosyl hydrolase family 48 genes in cellulolytic consortia enriched from thermophilic biocompost. Appl Environ Microbiol 2010, 76:3545-3553.

48. Stanley D, Geier MS, Denman SE, Haring VR, Crowley TM, Hughes RJ, Moore RJ: Identification of chicken intestinal microbiota correlated with the efficiency of energy extraction from feed. Vet Microbiol 2013, 164:85-92.

49. Smedley JG, Fisher DJ, Sayeed S, Chakrabarti G, McClane BA: The Enteric Toxins of Clostridium Perfringens. In Reviews of Physiology, Biochemistry and Pharmacology, Volume 152. Berlin: Springer Verlag; 2004:183-204.

50. Sawires YS, Songer JG: Clostridium perfringens: insight into virulence evolution and population structure. Anaerobe 2006, 12:23-43.
51. Van Immerseel F, De Buck J, Pasmans F, Huyghebaert G, Haesebrouck F, Ducatelle R: Clostridium perfringens in poultry: an emerging threat for animal and public health. Avian Pathol 2004, 33:537-549.

52. Qu A, Brulc JM, Wilson MK, Law BF, Theoret JR, Joens LA, Konkel ME, Angly F, Dinsdale EA, Edwards RA, Nelson KE, White BA: Comparative metagenomics reveals host specific metavirulomes and horizontal gene transfer elements in the chicken cecum microbiome. PLoS One 2008, 3:e2945.

53. Windisch W, Schedle K, Plitzner C, Kroismayr A: Use of phytogenic products as feed additives for swine and poultry. J Anim Sci 2008, 86:E140-E148.

54. Vandeplas $S$, Dubois Dauphin R, Beckers $Y$, Thonart $P$, Théwis A: Salmonella in chicken: current and developing strategies to reduce contamination at farm level. J Food Prot 2010, 73:774-785.

55. Ricke SC, Kundinger MM, Miller DR, Keeton JT: Alternatives to antibiotics: chemical and physical antimicrobial interventions and foodborne pathogen response. Poult Sci 2005, 84:667-675.

56. Over KF, Hettiarachchy N, Johnson MG, Davis B: Effect of organic acids and plant extracts on Escherichia coli 0157:H7, Listeria monocytogenes, and Salmonella Typhimurium in broth culture model and chicken meat systems. J Food Sci 2009, 74:M515-M521.

57. Heres L, Engel B, Urlings HAP, Wagenaar JA, Van Knapen F: Effect of acidified feed on susceptibility of broiler chickens to intestinal infection by Campylobacter and Salmonella. Vet Microbiol 2004, 99:259-267.

58. Van Immerseel F, Russell JB, Flythe MD, Gantois I, Timbermont L, Pasmans F, Haesebrouck F, Ducatelle R: The use of organic acids to combat salmonella in poultry: a mechanistic explanation of the efficacy. Avian Pathol 2006, 35:182-188.

59. Griffiths RI, Whiteley AS, O'Donnell AG, Bailey MJ: Rapid method for coextraction of DNA and RNA from natural environments for analysis of ribosomal DNA- and rRNA-based microbial community composition. Appl Environ Microbiol 2000, 66:5488-5491.

60. Rinttila T, Kassinen A, Malinen E, Krogius L, Palva A: Development of an extensive set of $16 \mathrm{~S}$ rDNA-targeted primers for quantification of pathogenic and indigenous bacteria in faecal samples by real-time PCR. J Appl Microbiol 2004, 97:1166-1177.

61. Oakley BB, Morales CA, Line JE, Seal BS, Hiett KL: Application of high-throughput sequencing to measure the performance of commonly used selective cultivation methods for the foodborne pathogen Campylobacter. FEMS Microbiol Ecol 2012, 79:327-336.

62. Blankenberg D, Gordon A, Von Kuster G, Coraor N, Taylor J, Nekrutenko A: Manipulation of FASTQ data with galaxy. Bioinformatics 2010, 26:1783-1785.

63. Oakley BB, Carbonero F, Dowd SE, Hawkins RJ, Purdy KJ: Contrasting patterns of niche partitioning between two anaerobic terminal oxidizers of organic matter. ISME J 2012, 6:905-914.

64. Schloss PD, Gevers D, Westcott SL: Reducing the effects of PCR amplification and sequencing artifacts on 16S rRNA-based studies. PLoS One 2011, 6:e27310.

65. Edgar RC: Search and clustering orders of magnitude faster than BLAST. Bioinformatics 2010, 26:2460-2461.

66. Schloss PD, Westcott SL, Ryabin T, Hall JR, Hartmann M, Hollister EB Lesniewski RA, Oakley BB, Parks DH, Robinson CJ, Sahl JW, Stres B, Thallinger GG, Van Horn DJ, Weber CF: Introducing mothur: open-source, platform-independent, community-supported software for describing and comparing microbial communities. App/ Environ Microbiol 2009, 75:7537-7541.

67. Wang Q, Garrity GM, Tiedje JM, Cole JR: Naive Bayesian classifier for rapid assignment of rRNA sequences into the new bacterial taxonomy. Appl Environ Microbiol 2007, 73:5261-5267.

68. R DCT: R: A Language and Environment for Statistical Computing. Vienna, Austria: R Foundation for Statistical Computing; 2013

69. Oksanen J., Blanchet FG, Kindt R, Legendre P, O'Hara RB, Simpson GL, Solymos P, Henry M, Stevens H, Wagner H (2010): vegan: Community Ecology Package. R package version 1.17-4.

70. McArdle $\mathrm{BH}$, Anderson MJ: Fitting multivariate models to community data: a comment on distance-based redundancy analysis. Ecology 2001, 82:290-297.

\section{doi:10.1186/s12917-014-0282-8}

Cite this article as: Oakley et al:: Successional changes in the chicken cecal microbiome during 42 days of growth are independent of organic acid feed additives. BMC Veterinary Research 2014 10:282. 